\title{
Effects of the dimple geometry on the isothermal performance of a hydrodynamic textured tilting- pad thrust bearing
}

\author{
Mostefa Kouider $^{*}$, Souchet Dominique ${ }^{2}$, Zebbar Djallel $^{3}$, Youcefi Abdelkader ${ }^{1}$ \\ ${ }^{1}$ Université des Sciences et de la Technologies d'Oran Mohamed Boudiaf, USTO-MB, BP 1505 El M'naouer, 31000 Oran, \\ Algérie \\ ${ }^{2}$ Institut Pprime, CNRS-Université de Poitiers - ENSMA, UPR 3346, Département de Génie Mécanique et Systèmes \\ Complexes, F86962 FUTUROSCOPE Chassenuile, France \\ ${ }^{3}$ Institut des Sciences et Technologies, Centre Universitaire de Tissemsilt El-Wancharissi, 38000, Algérie
}

Corresponding Author Email: kouider.mostefa@univ-usto.dz

https://doi.org/10.18280/ijht.360211

Received: 31 October 2017

Accepted: 6 March 2018

\section{Keywords:}

dimple geometry, hydrodynamic lubrication, pressure distribution, tiltingpad thrust bearings

\begin{abstract}
This paper is devoted to the analysis of effects of the dimple geometry on the hydrodynamic characteristics of a tilting pad thrust bearing. In a first step a discretization of Reynolds equation has been carried out by the finite difference method. It is followed by the development and validation of a hydrodynamic model used later for the examination of the influence of different surface dimples (radial, circumferential, rectangular...) on the hydrodynamic characteristics such as maximum pressure, friction torque and power loss. This study allowed highlighting that a suitable arrangement of the dimple contact surface area and also the depth of the dimple can contribute significantly to the improvement of the hydrodynamic characteristics of the tilting-pad thrust bearing.
\end{abstract}

\section{INTRODUCTION}

Thrusts bearings are important organs with support and guidance in rotation and are components of industrial and propulsion applications. Over the past years, extensive research activity has aimed at improving the performance of these components. There are two types fixed or tilting pads, the last bearings were invented by A. G. M. Michell in Australia and, independently, by A. Kingsbury in the USA [1]. Given the importance of these organs for rotating machines, several studies there are devoted to analyze their behavior and to study the different parameters which have an influence on their proper functioning (maximum pressure, load-carrying capacity and power loss). Experimentally and numerically in order to deduct theirs values.

For many years, the tribologists have privileged the smooth surfaces with very low roughness to limit friction between the torques of materials. Now, rough textured surfaces are at the center of all the interests because they significantly affect the flow of fluids. The majority of textured effects studies have been restricted to the study of thrust bearing with fixed pads geometry [2-3].

In 1974, Heubner [4] proposed an analysis of threedimensional thermohydrodynamic for fixed pad thrust bearing. It has taken into account the variation of viscosity with temperature following the three directions. In 1978, Frêne [5] studied theoretically and experimentally the thrusts bearings in isothermal regime working in two flow regimes: laminar and turbulent.

In 1983, Kim, Tanaka and Hori [6] developed a theoretical model to predict the thermohydrodynamic performance of the tilting pad thrust bearing in three-dimensional. They showed that the load and the friction torque are lower in the case of the three-dimensional analysis.

In 1986, Kaddouri [7] and Kaddouri, Souchet and Frêne [8] proposed a thermohydrodynamic theory for a tilting pad thrust bearing. The temperature of the disc is assumed to be constant, even the temperatures on the different sides of the pad, with the exception of the one to the interface film/ pad, are assumed constant and equal to the ambient temperature. The results obtained from this theory are compared with those obtained in [6].

In 2003, Markin, Glavatskih and McCarthy [9] presented the finite element solution for a tilting pad thrust bearings and showed that this method is advantageous for the hydrodynamic performance. The results obtained are in agreement with those found by experimentation.

In 2007, Bouyahia et al. [10] developed a numerical model to predict the influence of non-Newtonian character of incompressible lubricants on the operation of hydrodynamic thrust bearings. The authors have chosen four rheological models: The Power law (pseudo-plastic behavior), the Bingham, and the Herschel-Bulkley (viscoplastic behavior).

The mathematical model is based on the solution of a generalized Reynolds equation established using the concept of Generalized Newtonian Fluids. The temperature effect is taken into account through the resolution of energy equation in the film and Laplace's equation in the pad. The evolution of pressure and temperature fields, according to the characteristics of non-Newtonian lubricants, is analyzed. Load capacity, friction torque, and power loss are also calculated as interesting parameters from an industrial point of view.

All these researchers have studied the thrust bearing for the case plan without texturing or dimple on the surfaces of solid parts. After this, there has been great interest in the textured 
effect. Some researchers have used commercial Computational Fluid Dynamics (CFD) techniques to obtain a better estimate of the hydrodynamics characteristics of the thrusts bearings, when others have developed numerical model. Either by utilizing Reynolds equation, or by using CFD, the results of such studies for textured pad thrust bearings prove the existence of an optimal design for certain geometry and operating profile.

In 2007, V. G. Marian et al. [11] presented a theoretical and experimental analysis of a partially textured thrust bearing with square dimples, these authors obtained a good correlation between the theoretical and experimental results.

In 2010, Dobrica et al. [12] presented an optimization of the geometry of the texture applied in the case of the pads to be inclined sides; these authors utilized a mass-conserving numerical approach.

In 2011, Papadopoulos et al. [13] presented an optimization study where they used a CFD code to solve the Navies-stokes and energy equations; the authors neglected the effects due to the cavitation. The optimization goal is the maximization of the bearing load carrying capacity.

In 2013 Charitopoulos et al. [14] have used the CFD code to simulate the thermohydrodynamic performance and mechanical deformations of a fixed geometry thrust bearing with artificial surface texturing.

In 2014, Satish et al. [15] investigated the influence of dimple geometry on fully textured hybrid thrust pad bearing and operating with non-Newtonian lubricant. By using the Finite Element Method, the simulated results indicate that the values of load carrying capacity, frictional power loss, maximum pressure and fluid film stiffness coefficient are significantly affected by the behavior of lubricant.

In 2015, Fillon et al. [16] presented a numerical investigation for a tilting-pad thrust bearings with pocket in both isothermal and thermohydrodynamic regimes. The authors analyzed the influence of pocket depth and pocket size on the main bearing characteristics.

In 2015, Henry et al. [17] studied experimentally the influence of surface texturing on the steady-state behavior thrust bearing. The authors show that, for the studied configurations, the textured thrust bearings can help to reduce friction up to $30 \%$ at low loads while for heavy loads, their performance is equivalent or even lower than that of an untextured planar bearing.

In 2017, Bian Guo [18] presented a numerical investigation of the effects of micro spherical and cylindrical dimples on the load-carrying capacity of the case of the journal bearing with axial groove, aiming to obtain the best lubrication performance.

Recently, Gherca et al. [19] presented a numerical investigation on the influence of surface texturing on the hydrodynamic performance of a two-dimensional parallel slider bearing operating in both steady-state and transient lubrication regime with finite element method.

The paper is organized as follows. The mathematical formulations of the problem are first presented, followed by the validation of the model. Subsequently, the results are presented and discussed, and, finally, the main conclusions are summarized.

\section{MATHEMATICAL FORMULATION OF THE PROBLEM}

The equations of hydrodynamic lubrication for Newtonian fluids take different forms depending on the assumptions made. These equations for viscous fluids to thin, taking into account the geometric and kinematic conditions, to determine the characteristics of a flowing thin film and especially its lift. They are derived from the equations of continuum mechanics applied to a Newtonian fluid.

\subsection{Reynolds equation}

The Reynolds equation is obtained from the NaviersStockes and continuity equations for an incompressible, isoviscous, steady-state and laminar flow fluid. The Reynolds equation for a tilting pad thrust bearing in cylindrical coordinates is given in (Eq.1):

The tilting pad thrust bearing is illustrated in Figure 1.
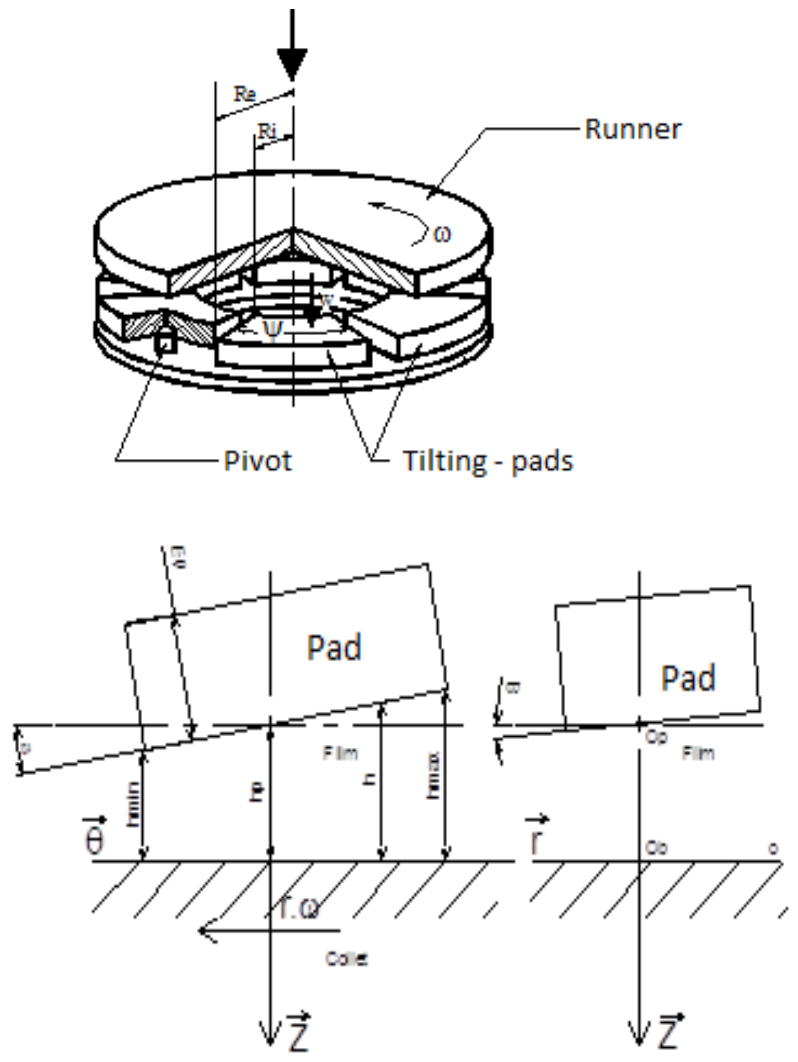

Figure 1. Schematic diagram of a tilting - pad thrust bearing

$\frac{\partial}{\partial r}\left[r h^{3} \frac{\partial P}{\partial r}\right]+\frac{1}{r} \frac{\partial}{\partial \theta}\left[h^{3} \frac{\partial P}{\partial \theta}\right]=6 \mu r \omega \frac{\partial h}{\partial \theta}$

The use of variables without dimension allows the generalization of the problem, one poses:

$\begin{array}{cc}r=\bar{R} R_{m} & \mu=\mu_{0} \bar{\mu} \quad \theta=\bar{\theta} \\ P=\frac{\mu_{0} \omega R_{m}^{2}}{h_{p}^{2}} \bar{P} & h=h_{p} H\end{array}$

By putting these equations in equation (1) we obtain the Reynolds equation in non-dimensional form (Eq. 3):

$\frac{\partial}{\partial \bar{R}}\left[\bar{R} H^{3} \frac{\partial \bar{P}}{\partial \bar{R}}\right]+\frac{1}{\bar{R}} \frac{\partial}{\partial \bar{\theta}}\left[H^{3} \frac{\partial \bar{P}}{\partial \bar{\theta}}\right]=6 \bar{\mu} \bar{R} \frac{\partial H}{\partial \bar{\theta}}$ 
The pressure at the boundaries is assumed to be equal to zero.

$\left\{\begin{array}{l}\bar{P}\left(\overline{R_{i}}, \theta\right)=\bar{P}\left(\overline{R_{e}}, \theta\right)=0 \\ \bar{P}\left(\bar{R}, \theta_{i}\right)=\bar{P}\left(\bar{R}, \theta_{e}\right)=0\end{array}\right.$

\subsection{Film thickness equation}

To solve Reynolds equation, it is therefore necessary to know the expression of the film thickness, this equation is given by:

$$
\begin{aligned}
H(\bar{\theta}, \bar{R})=1 & +\frac{\bar{R}_{p} R_{m}}{h_{p}} \sin (\beta)-\frac{\bar{R} R_{m}}{h_{p}} \\
& {[\cos (\bar{\theta}) \sin (\beta)-\sin (\bar{\theta}) \sin (\alpha)]+\Delta \bar{H} }
\end{aligned}
$$

In the equation above, $\Delta \bar{H}$ is the film thickness variation due to the dimple surface.

\subsection{Equilibrium of a pad}

One of the characteristics that represent the calculation in the tilting pad thrust bearing it is the static equilibrium of the pad; this equilibrium requires the annulations of the moments in the radial and circumferential directions.

These equations are given by:

$$
\left\{\begin{array}{l}
\overline{M_{r}}=\int_{\overline{R_{i}}}^{\overline{R_{e}}} \frac{\int_{\theta_{\text {out }}}}{\theta_{\text {in }}} P(\bar{\theta}, \bar{R}) \bar{R}^{2} \sin (\theta) d \bar{R} d \bar{\theta}=0 \\
\overline{M_{\theta}}=\int_{R_{i}}^{R_{e}} \int_{\theta_{\text {in }}}^{\theta_{\text {out }}} P(\bar{\theta}, \bar{R}) \bar{R}\left(\overline{R_{p}}-\bar{R}\right) \cos (\theta) d \bar{R} d \bar{\theta}=0
\end{array}\right.
$$

The above system of equations is solved using the NewtonRaphson method modified.

\subsection{Load and friction torque}

The resolution of the Reynolds equation allows the determination of the load supported by each pad by integrating the pressure field across the pad section (Eq. 7).

$$
\overline{W_{P}}=\int_{R_{i}}^{\overline{R_{e}}} \overline{\theta_{\text {in }}} \int_{\theta_{\text {out }}} P(\bar{\theta}, \bar{R}) \bar{R} d \bar{R} d \bar{\theta}
$$

The viscous friction torque calculated at collar level and is obtained by integrating the tangential shear stress within the lubricant and is given by (Eq. 8).

$$
\overline{C_{f}}=\int_{R_{i}}^{\overline{R_{e}}} \overline{\theta_{\text {out }}} \frac{\bar{\mu}}{\overline{\theta_{\text {in }}}} \frac{\partial \overline{V_{\theta}}}{\partial \bar{Z}} \bar{R}^{2} d \bar{R} d \bar{\theta}
$$

\section{MODEL VALIDATION}

The validation of the model used in the present study was performed by comparing the results of respective cases with those in published literature. The hydrodynamic problem of tilting pad thrust bearings without textured has been solved by Souchet D. [20] and Bouyahia F. [21]

The results of this study are in good agreement with those obtained by Souchet D. [20] and Bouyahia F. [21] for two rotational speeds (500 and 3000) rpm. The results are presented in the dimensional form on the Table 1.

Table1. Comparison between the current study and other studies [20] and [21]

\begin{tabular}{ccccc}
\hline Parameter & \multicolumn{2}{c}{ Present Study } & {$[20]$} & {$[21]$} \\
\hline Rotational speed, N (rpm) & 500 & 3000 & 500 & 3000 \\
\hline Inner radius / Outer radius $(\mathrm{mm})$ & $28.5 / 45$ & $187.5 / 322.5$ & $28.5 / 45$ & $187.5 / 322.5$ \\
\hline $\begin{array}{c}\text { Angles of Inclinations, } \\
\alpha / \beta\end{array}$ & \multirow{2}{*}{$(0.000 /-0.0003)$} & \multirow{2}{*}{ Not fixed } & \multirow{2}{*}{$(0.000 /-0.0003)$} & \multirow{2}{*}{ Not fixed } \\
\hline Film thick. at pivot, hp $(\mu \mathrm{m})$ & \multicolumn{2}{c}{100} \\
\hline Dynamic viscosity, $\mu(\mathrm{Pa} . \mathrm{s})$ & 0.0220 & 0.0252 & 0.0220 & 0.0252 \\
\hline Pad angle, $\psi(\mathrm{deg})$ & 30 & 28 & 30 & 28 \\
\hline Min. film thickness $(\mu \mathrm{m})$ & 97.3 & 18.9 & 97.3 & 18.9 \\
\hline Max. Pressure $(\mathrm{MPa})$ & 1.8 & 11.9 & 1.7 & 11.9 \\
\hline Max. Number of Reynolds & 9.5 & 507.8 & 9.5 & 507.8 \\
\hline Min. Number of Reynolds & 5.7 & 30.7 & 5.7 & 30.7 \\
\hline Load per pad, Wp $(\mathrm{N})$ & 0.3 & 48766 & 0.3 & 48646 \\
\hline Friction torque $(\mathrm{N} . \mathrm{m})$ & 0.005 & 111.3 & 0.005 & 114.5 \\
\hline Power loss $(\mathrm{W})$ & 0.26 & 34950.3 & 0.26 & 35981.2 \\
\hline
\end{tabular}

\section{TEXTURES CHARACTERISTICS}

This study examines the influence of the dimples geometry on the hydrodynamic performance of a tilting pad thrust bearings. Four types of dimples on the same tilting pad thrust bearing have been chosen for the present study: case 1: a bearing with circumferential grooves, case 2 : a bearing with radial grooves, case 3: a bearing with rectangular dimples and case 4: a dimple bearing.

The textured area was fixed at $77 \%$ of the pad length and
$80 \%$ of the pad width for the first three cases, and $10 \%$ of the pad length and $20 \%$ of the pad width for the case 4 as shown in Figure 2.

\section{RESULTS AND DISCUSSION}

\subsection{Numerical solution}

The Reynolds Equation Eq. (3) with appropriate boundary 
conditions is discretized by the finite difference method, the linearization of the non-linear system of equations and the resolution of the resulting linear system is performed by the algorithm of Gauss - Seidel with over-relaxation coefficient.

The values of the operational parameters of this study are presented in Table 2 .

Table 2. Geometrical characteristics of the tilting pad thrust bearing

\begin{tabular}{|c|c|}
\hline Parameter & Value \\
\hline Rotational speed, $\omega(\mathrm{rpm})$ & $500-3000$ \\
\hline Inner radius / Outer radius, $R_{\mathrm{i}}, R_{\mathrm{e}}(\mathrm{mm})$ & $187.5 / 322.5$ \\
\hline Dynamic viscosity, $\mu$ (Pa.s) & 0.0252 \\
\hline Film thickness at pivot, $H p(\mu \mathrm{m})$ & 100 \\
\hline Number of pad & 12 \\
\hline Pad angle, $\theta \mathrm{p}(\mathrm{deg})$ & 28 \\
\hline Pivot circumferential position, $\quad \psi(\mathrm{deg})$ & 17.38 \\
\hline Pivot radius, $R_{P}(\mathrm{~mm})$ & 255.00 \\
\hline Depth of dimple, $\Delta H(\mu \mathrm{m})$ & $20-30-40$ \\
\hline Type of pivot & Linear contact \\
\hline \multirow{4}{*}{ Number of dimple } & Case 1: 3 \\
\hline & Case 2: 4 \\
\hline & Case 3: $3 * 4$ \\
\hline & Case 4: 1 \\
\hline \multirow{4}{*}{ Length of dimple, L_text (deg) / Width of dimple, W_text (mm) } & Case 1: $21.67 / 13.5$ \\
\hline & Case 2: $1.89 / 108$ \\
\hline & Case 3: $2.83 / 13.5$ \\
\hline & Case 4: $2.83 / 13.5$ \\
\hline
\end{tabular}
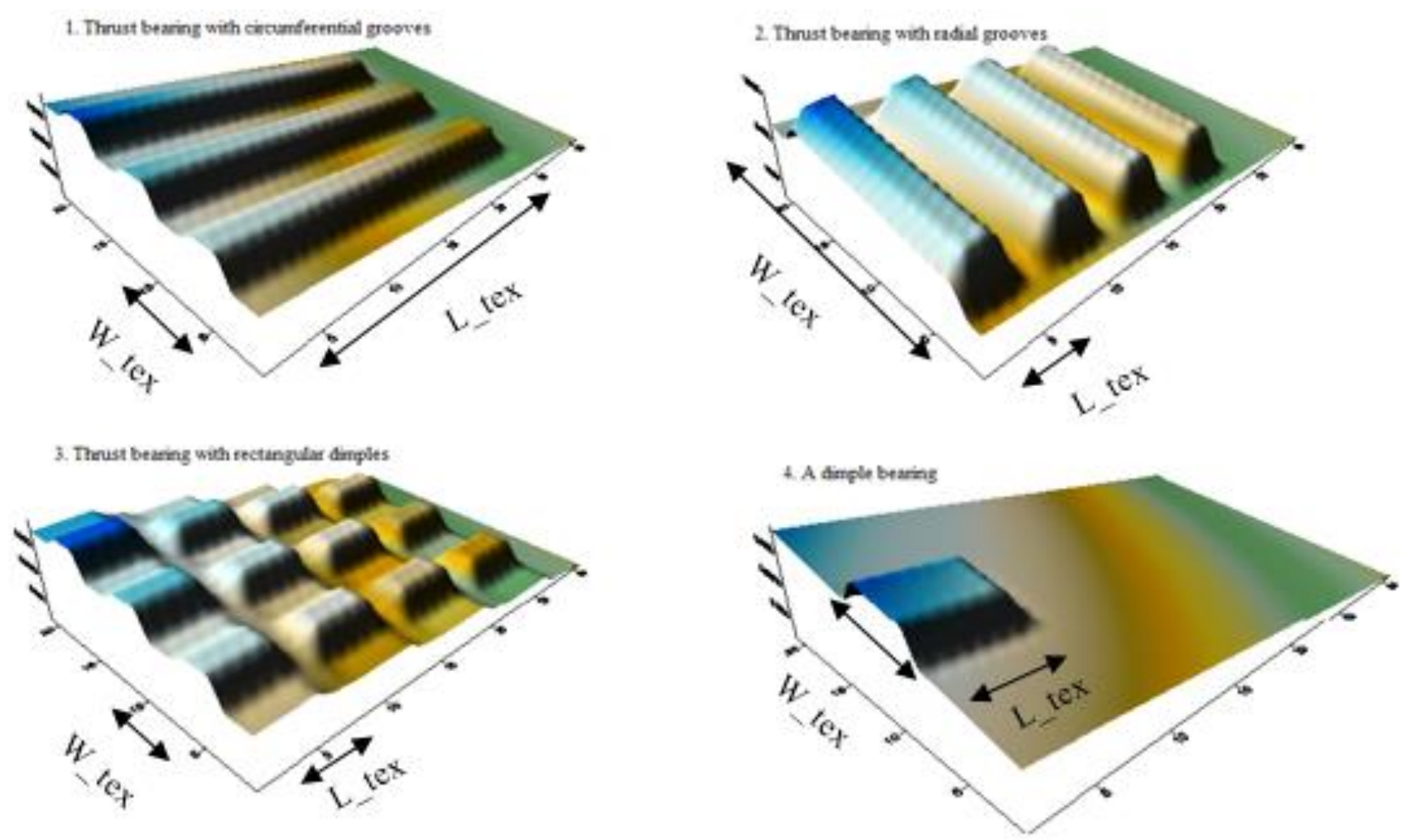

Figure 2. The different cases studies of the dimples geometry

\subsection{Variation of pressure}

Figure 3 shows the pressure distributions in the pad, for a depth of dimple equal to $20 \mu \mathrm{m}$ and a rotational speed of 3000 rpm, corresponding respectively for a thrust bearing with circumferential grooves (1), a thrust bearing with radial grooves (2), a thrust bearing with rectangular dimples (3), and a thrust bearing with a dimple in the medium of the pad (4).

For all cases the maximum pressure is obtained on the limit of the dimple in the circumferential direction and in position center of the pad in the radial direction.

The figure also shows that the maximum pressure is obtained for the case of thrust bearing with rectangular dimples, and the minimum pressure is obtained for the case of thrust bearing with a dimple in the center of the entry of the pad.

Furthermore, the influence of depth of the dimple on the pressure is shown more clearly in Figure 5 where the pressure profiles at the bearing mid sector are shown for all thrusts bearings studied in this work. 

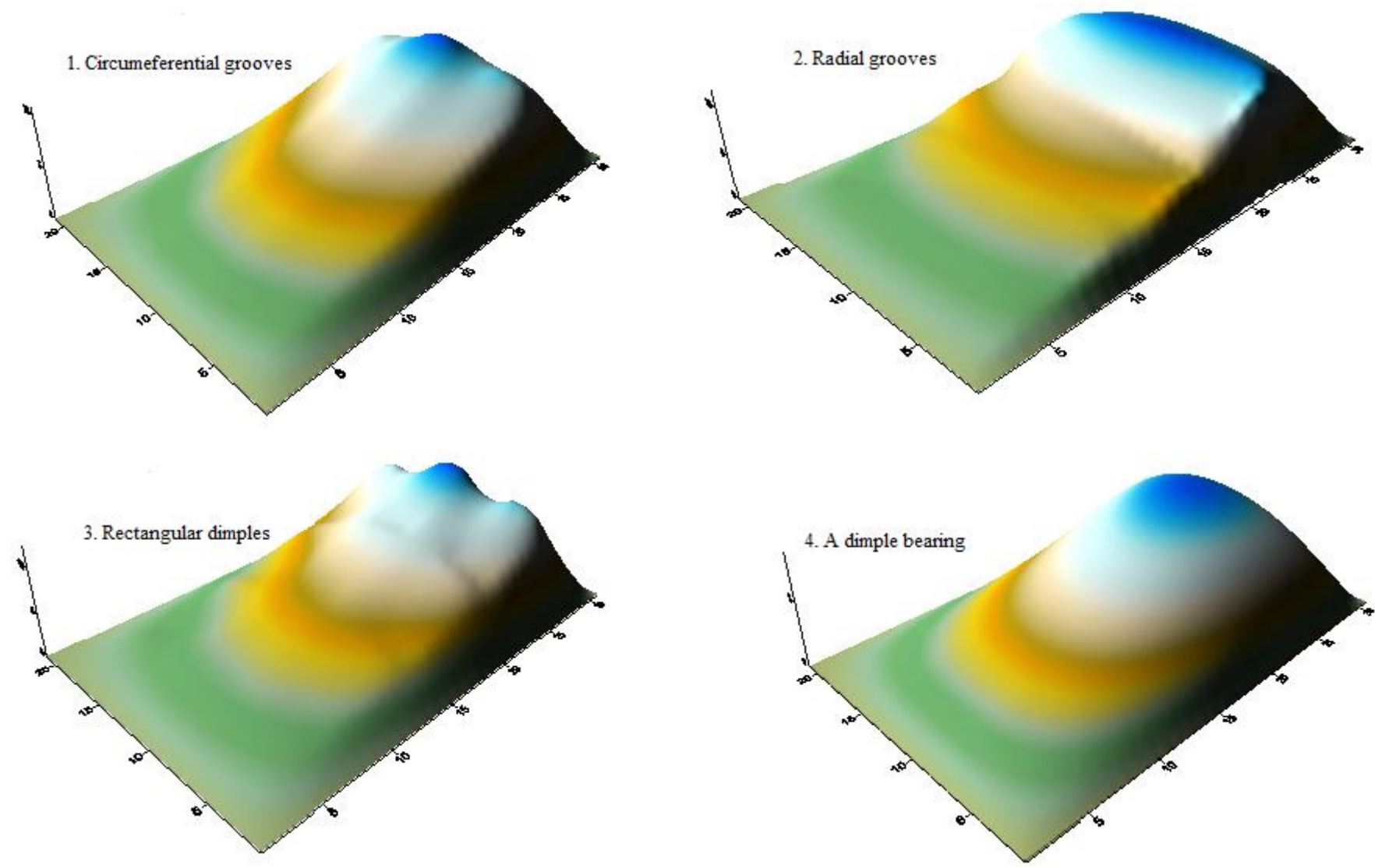

Figure 3. Variation of pressure for different cases studies in 3D

In table 3, a comparison has been performed considering the four types of geometry studies in the present work, for a rotational speed equal to $3000 \mathrm{rpm}$. Various operating characteristics are presented (maximal pressure, friction torque, power loss, the oil flow rate at the inlet of the pad, and the load per pad)

The maximum of the load is obtained for a bearing with radial grooves, and a minimum for a case with a dimple bearing.

Consequently, friction forces and therefore power loss is proportional to load.

With regard to the oil flow rate at the inlet of the pad, the maximum is obtained for the case of a bearing with circumferential grooves.

Table 3. Performances indices for different cases

\begin{tabular}{ccccc}
\hline Parameter & $\begin{array}{c}\text { case 1: } \\
\text { a bearing with } \\
\text { circumf. } \\
\text { grooves }\end{array}$ & $\begin{array}{c}\text { case 2: } \\
\text { a bearing with } \\
\text { radial grooves }\end{array}$ & $\begin{array}{c}\text { case 3: } \\
\text { a bearing with } \\
\text { rectangular } \\
\text { dimples }\end{array}$ & $\begin{array}{c}\text { case 4: } \\
\text { a dimple } \\
\text { bearing. }\end{array}$ \\
\hline Rotational speed, $\omega(\mathrm{rpm})$ & & \multicolumn{2}{c}{3000} & \\
\hline The maximum pressure, $(\mathrm{MPa})$ & 8.80 & 11.76 & 12.58 & 8.67 \\
\hline $\begin{array}{c}\text { The oil flow rate at the inlet of the } \\
\text { pad, }(\mathrm{l} / \mathrm{min})\end{array}$ & 52.44 & 52.12 & 52.40 & 50.59 \\
\hline Friction torque, $(\mathrm{N} . \mathrm{m})$ & 90.25 & 116.19 & 96.19 & 87.98 \\
\hline Power losses, $(\mathrm{KW})$ & 28.35 & 36.50 & 30.22 & 27.64 \\
\hline Load per pad, $(\mathrm{KN})$ & 60.45 & 76.93 & 67.97 & 59.59 \\
\hline
\end{tabular}

Figure 4 shows the variation of the pressure in the circumferential and radial directions for three different positions in each direction and this for a depth of dimple equal to $20 \mu \mathrm{m}$ and a rotational speed of $3000 \mathrm{rpm}$ corresponding respectively: to the thrust bearing without dimples (a) and (b), thrust bearing with grooves in the circumferential direction (c) and (d), thrust bearing with grooves in the radial direction (e) and (f), thrust bearing with rectangular dimples (g) and (h) and thrust bearing with dimple in the middle of the pad (i) and (j).
In the circumferential direction, the maximum of pressure is observed in the position radial $\mathrm{R}_{2}=255 \mathrm{~mm}$ (mid sector) for all cases studies, while the pressure at $R_{1}$ and $R_{3}$ decreases. The maximum pressure is reached for the case of a thrust with rectangular dimples and that is worth $12 \mathrm{MPa}$ at the angular position $23.33^{\circ}$ from the entry of the pad.

In the radial direction, the maximum pressure is obtained for the angular position $\left(\theta_{3}\right)$ for all the cases studied, while the pressure following $\left(\theta_{2}\right)$ and $\left(\theta_{1}\right)$ is lower. 

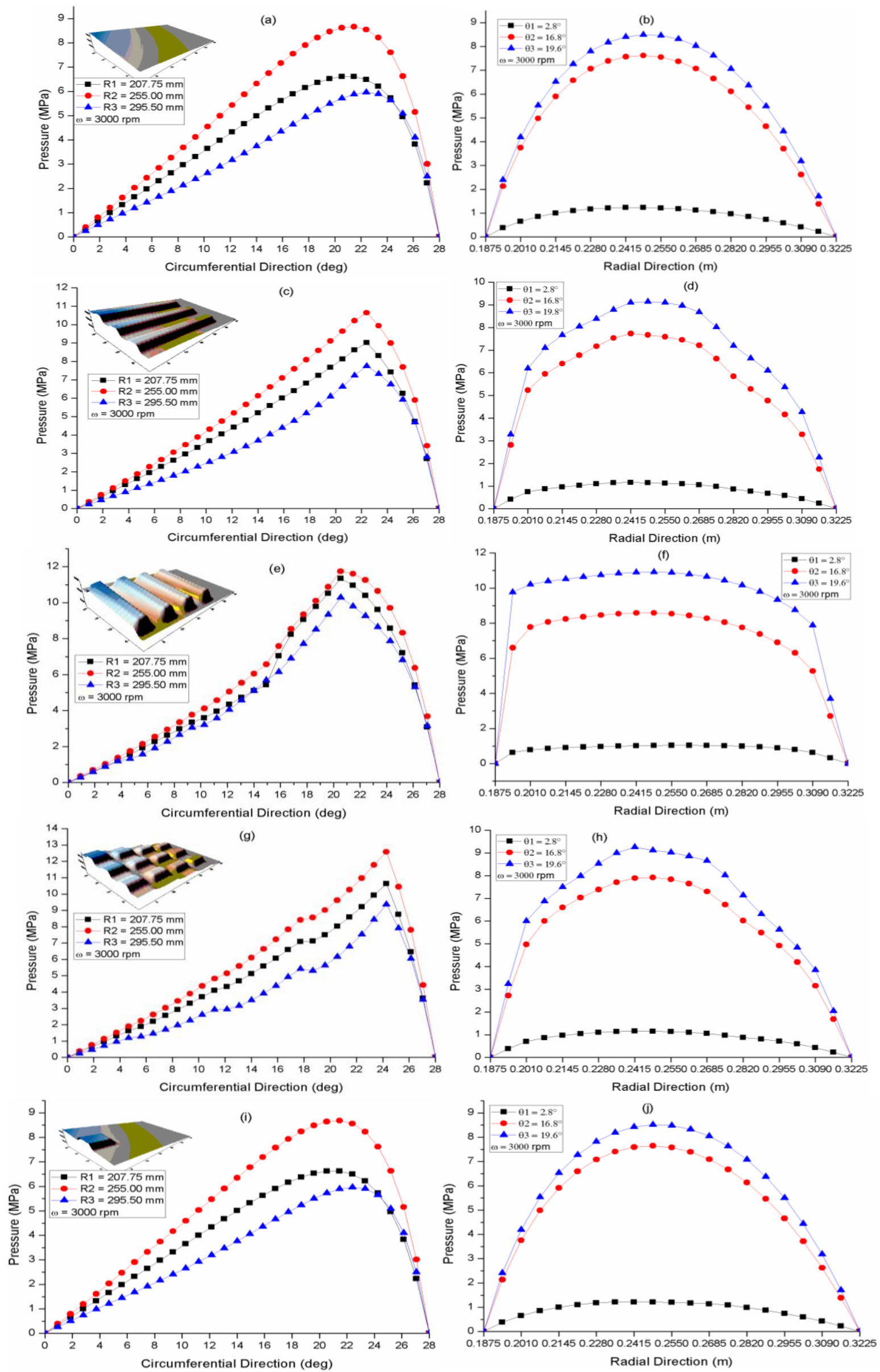

Figure 4. Pressure distribution of $(\mathrm{a}, \mathrm{b})$ plain bearing, $(\mathrm{c}, \mathrm{d})$ bearing with circumferential grooves, $(\mathrm{e}, \mathrm{f})$ bearing with radial grooves, $(\mathrm{g}, \mathrm{h})$ bearing with rectangular dimples, $(\mathrm{i}, \mathrm{j})$ a dimple bearing versus two directions. Results are presented for three positions for each directions 


\subsection{Influence of the depth of the dimple}

Figure 5 shows the influence of the dimple depth on the variation in pressure for rotational speed of $3000 \mathrm{rpm}$ in the radial and circumferential directions for a position angular $\theta=16,8^{\circ}$ and a position radial $\mathrm{R}=255 \mathrm{~mm}$ respectively. The results show that this influence is observed at a position of the pivot in the circumferential direction, and the maximum corresponds for the maximum value of the depth of the dimple, except for the case of the thrust bearing with dimple in the middle of the pad, in this case the results are almost identical for different depth of dimple in the radial and circumferential directions.

In the radial direction, increasing the depth of the dimple causes a slight increase in the pressure field.
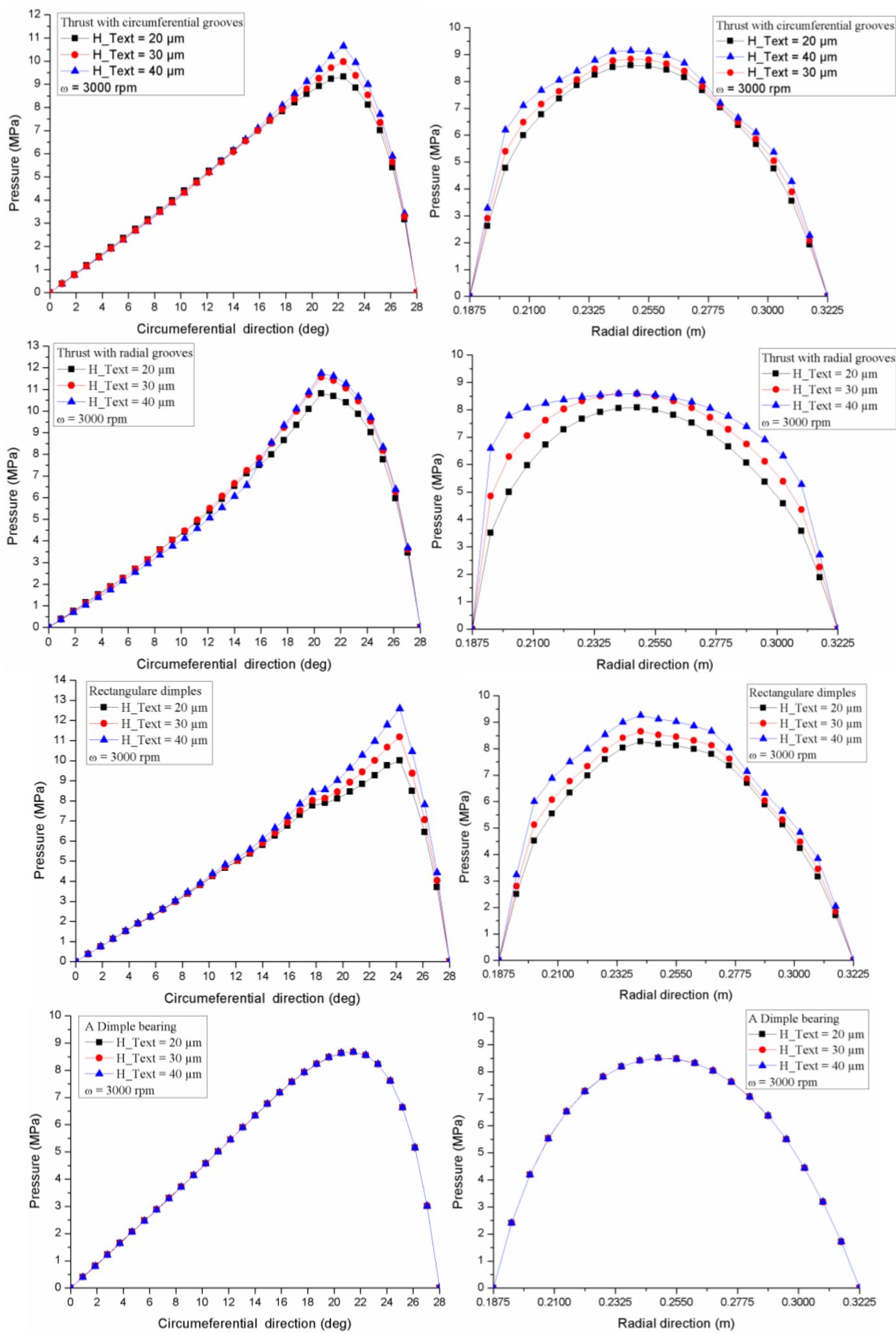

Figure 5. Influence of dimple depth 


\subsection{Position of the dimple}

The influence of the position of the dimple for three separate positions to the entry of the pad (case 1), middle of the pad (case 2) and the output of the pad (case 3 ) is illustrated in Figure 6.

This distribution is shown along three different radiuses for each case for a rotational speed of $3000 \mathrm{rpm}$ and a depth of dimple equal to $20 \mu \mathrm{m}$.

In the case 1, the dimple is located at the entry of the pad; this position does not have an influence on the field of pressure.
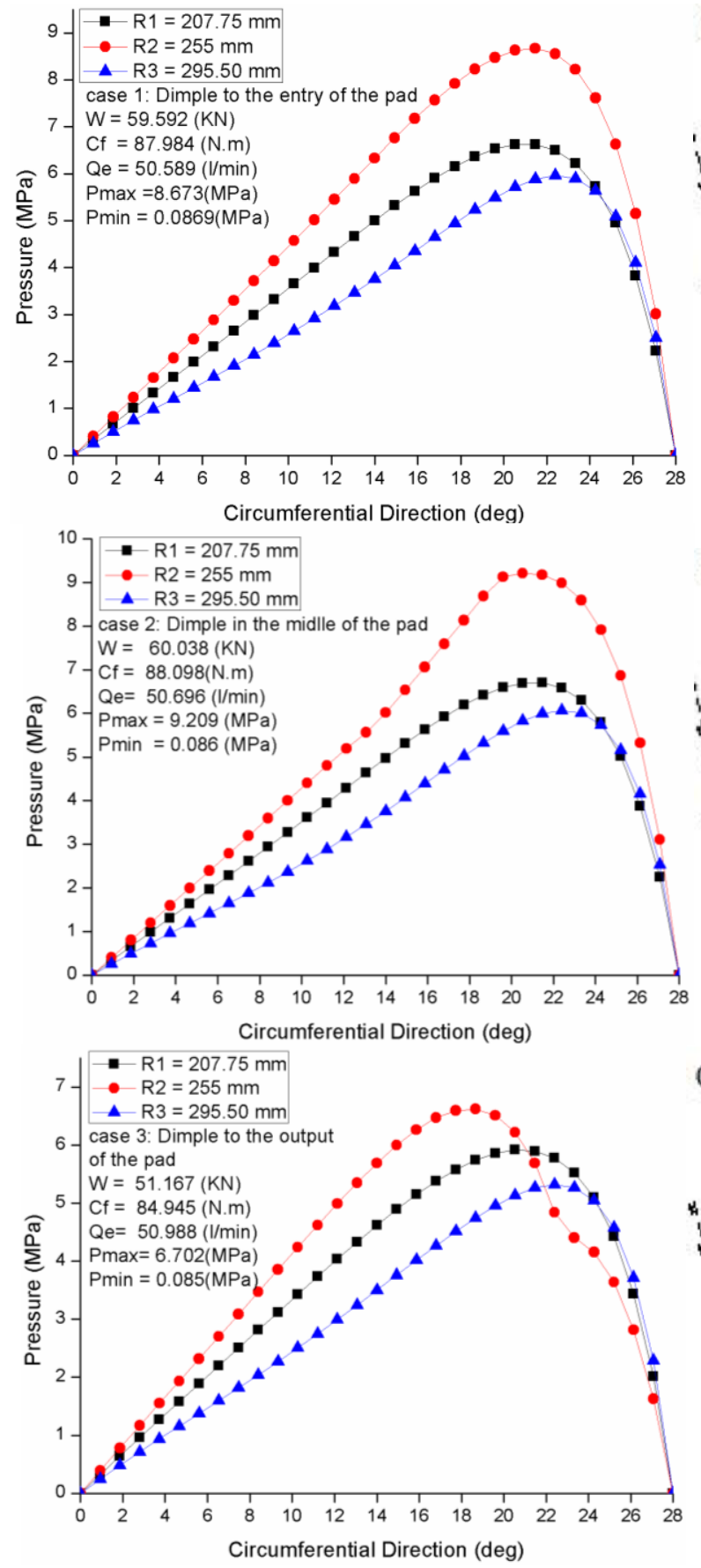

Figure 6. Influence of the position of the dimple

\subsection{Variation of friction torque}

Figure 7 shows the variations in friction torque calculated for all the configurations of tilting-pad thrust bearings, as a

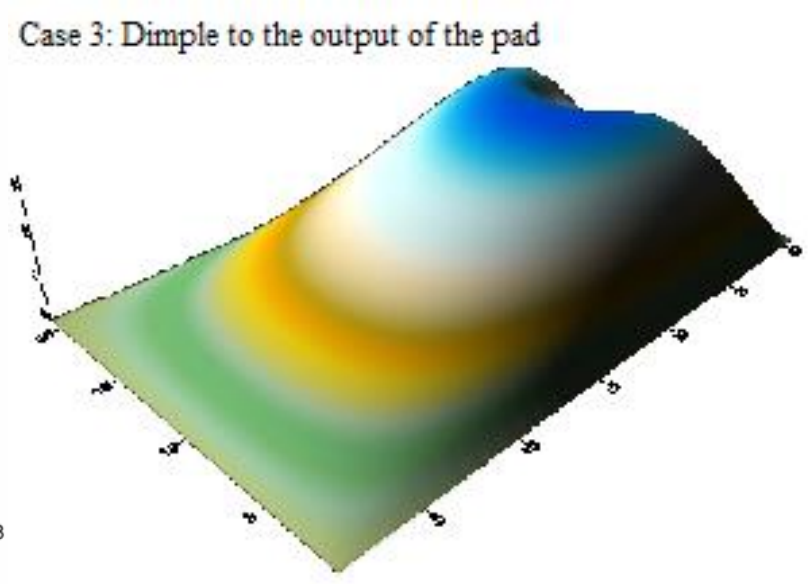

For the case where the dimple is located in the middle of the pad (case 2), we obtained a maximum pressure and the load capacity maximum.

The distribution of the pressure obtained for the case where the dimple is located at the outlet of the pad is the most influenced, this position leads to a decrease in the maximum pressure and the load capacity.

When we compare these results it becomes more evident that for optimum performance in terms of load capacity for the case of a dimple located on the average radius it must be placed in the meadows of the center of the pad. These results are similar to those of Andrei Gherca [3].
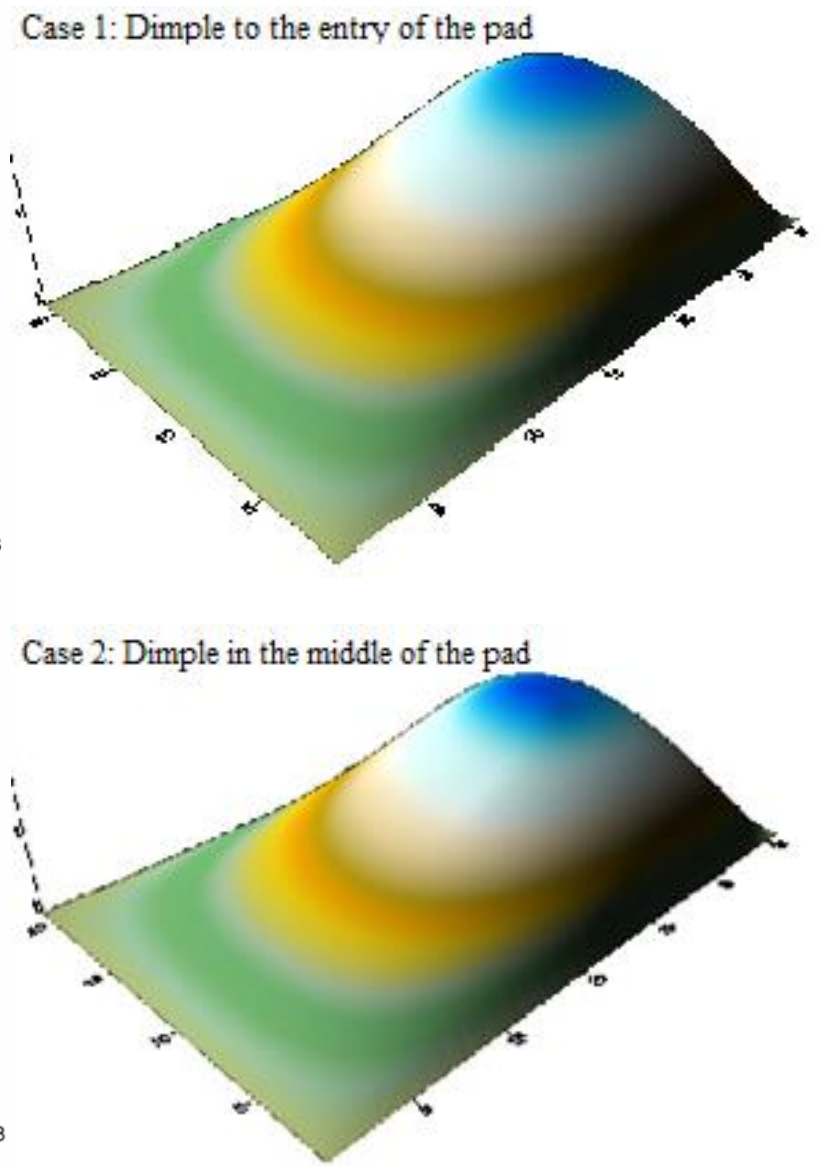
radial grooves. The discrepancies in the friction torque are mainly due to the average film thickness.

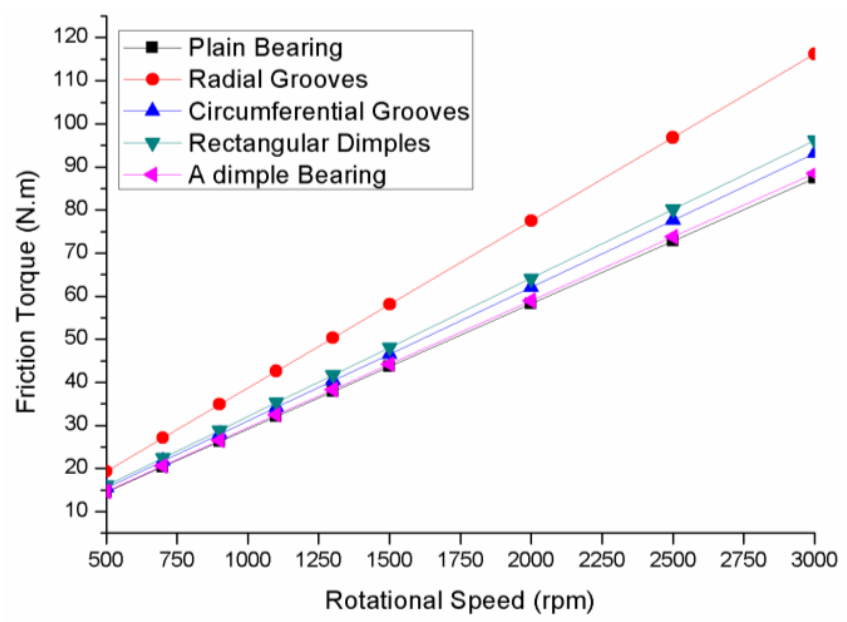

Figure 7. Variation of the friction torque

\section{CONCLUSIONS}

This paper proposes a numerical approach for analyzing the effects of the dimples geometry in the tilting-pad thrust bearing. An isothermal model was used in this case to determine the hydrodynamic characteristics of the thrust bearing. The obtained results shows that the values of these characteristics of the thrust bearing as maximum pressure, power loss and friction torque are influenced by the type of the dimple. Moreover, the thrust bearing with dimples in the radial direction presents the maximum values.

For the influence of the depth of the dimple, it can be noted that the pressure values are almost the same on the entire sector of the pad, except in the neighborhood of the position of the pivot where there is a gap between the values of the pressure and this for the thrusts bearings with rectangular dimples and grooves in the radial and circumferential directions. For the case of the thrust with dimple in the center of the sector of the pad the depth has not influence.

Finally, comparing the results obtained for different dimples positions located in the middle radius of the pad, the optimal performance in load capacity can be obtained for the case of a dimple placed in a position close to the pivot position.

\section{ACKNOWLEDGMENT}

The corresponding author thanks M. Hajjam Mohamed from University of Poitiers for these encouragements.

\section{REFERENCES}

[1] Wasilczuk M. (2015). Friction and lubrication of large tilting-pad thrust bearings. Lubricants 3(2): 164-180. http://dx.doi.org/10.3390/lubricants3020164

[2] Henry Y. (2013). Experimental analysis of the effect of pads texturing on fixed geometry hydrodynamic thrust bearings behavior. Ph.D. Dissertation. University of Poitiers, France.

[3] Gherca A. (2013). Modélisation de la lubrification des surfaces texturées - Application à la butée en régime hydrodynamique. Ph.D. Dissertation. University of Poitiers, France.

[4] Huebner KH. (1974). A three dimensional analysis of sector thrust bearing. ASLE Trans. 17(1): 62-73. http://dx.doi.org/10.1080/05698197408981439

[5] Frêne J. (1978). Tapered land thrust bearing operating in both laminar and turbulent regimes. ASLE Tran. 21(3): 243-249. http://dx.doi.org/10.1080/05698197808982881

[6] Kim KW, Tanaka M, Hori Y. (1983). A threedimensional analysis of thermohydrodynamic performance of sector-shaped, tilting-pad thrust bearings. Trans ASME, Journal of Lubrication Technology 105(3): 406-413. http://dx.doi.org/10.1115/1.3254625

[7] Kaddouri M. (1986). Détermination des caractéristiques des butées hydrodynamiques: Influence des phénomènes thermiques. Ph.D. Dissertation. Université de Poitiers, France.

[8] Kaddouri M, Souchet D, Frêne J. (1988). Analyse des effets thermiques dans une butée à patins oscillants. Rev. Roum. Sci. Tech. Méc. Appl. 33(5): 455-473.

[9] Markin D, Mc. Carthy DMC, Glavatskih SB. (2003). A FEM approach to simulation of tilting-pad thrust bearing assemblies. Tribology International 36(11): 807-814. http://dx.doi.org/10.1016/S0301-679X(03)00097-5

[10] Bouyahia F, Hajjam M, Khlifi ME, Souchet D. (2006). Three-dimensional non-Newtonian lubricants flows in sector-shaped, tilting-pads thrust bearings. Proceedings of the Institution of Mechanical Engineers, Part J: Journal of Engineering Tribology 220(3): 75-84. http://dx.doi.org/ 10.1243/13506501JET92

Marian VG, Kilian M, Scholz W. (2007). Theoretical and experimental analysis of a partially textured thrust bearing with square dimples. Proceedings of the Institution of Mechanical Engineers, Part J: Journal of Engineering Tribology 221(7): 771-778 http://dx.doi.org/10.1243/13506501JET292

[11] Dobrica M, Fillon M, Pascovici M, Cicone T. (2010). Optimizing surface texture for hydrodynamic lubricated contacts using a mass-conserving numerical approach. Proceedings of the Institution of Mechanical Engineers, Part J: Journal of Engineering Tribology 224(8): 737750. http://dx.doi.org/10.1243/13506501JET673

[12] Papadopoulos CI, Efstathiou EE, Nikolakopoulos P. G., Kaiktsis L. (2011). Geometry optimization of textured three-dimensional micro-thrust bearings. J Tribol 133(4): 041702. http://dx.doi.org/10.1115/1.4004990

[13] Charitopoulos A, Fouflias D, Papadopoulos CI, Kaiktsis L, Fillon M. (2014). Thermohydrodynamic analysis of a textured sector-pad thrust bearing: effects on mechanical deformations. Mechanics \& Industry 15(5): 403-411. http://dx.doi.org/10.1051/meca/2014048

[14] Sharma Satish C, Yadav Saurabh K. (2014). Performance analysis of a fully textured hybrid circular thrust pad bearing system operating with non-newtonian lubricant. Tribology International 77: 50-64. http://dx.doi.org/10.1016/j.triboint.2014.04.013

[15] Fillon M, Wodtke M, Wasilczuk M. (2015). Effect of presence of lifting pocket on the THD performance of a large tilting-pad thrust bearing. Friction 3(4): 266-274. http://dx.doi.org/10.1007/s40544-015-0092-4

[16] Henry Y, Bouyer J, Fillon M. (2015). An experimental analysis of the hydrodynamic contribution of textured thrust bearings during steady state operation - 
comparison with the untextured parallel surface configuration. Journal of Engineering Tribology, Part J. 229(4):

https://doi.org/10.1177/1350650114537484

$362-375$

[17] Bian G. (2017). Optimal surface texture design of journal bearing with axial grooves. International Journal of Heat $\begin{array}{lll}\text { and } & \text { Technology } & \text { 267-272. }\end{array}$ http://dx.doi.org/10.18280/ijht.350206

[18] Gherca A, Fatu A, Hajjam M, Maspeyrot P. (2016). Influence of surface texturing on the hydrodynamic performance of a thrust bearing operating in steady-state and transient lubrication regime. Tribology International 102: $305-318$ http://dx.doi.org/10.1016/j.triboint.2016.05.041

[19] Souchet

D.

(1991).

Comportement Thermohydrodynamique des Butées A Patins Oscillants en Régime Laminaire et Turbulent, Ph.D. Dissertation. University of Poitiers, France.

[20] Bouyahia F. (2004). Analyse thermohydrodynamique du comportement des contacts lubrifiés par des fluides non Newtoniens - application aux Butées A Patins Oscillants. Ph.D. Dissertation. University of Poitiers, France.

\section{NOMENCLATURE}

$\begin{array}{ll}h & \text { Pad thickness, } \mathrm{m} \\ h_{p} & \text { Film thickness at pivot location, } \mathrm{m} \\ P & \text { Pressure, } \mathrm{Pa} \\ Q_{e} & \text { Flow rate, } 1 / \mathrm{min} \\ R_{e} & \text { Pad outer radius, } \mathrm{m} \\ R_{i} & \text { Pad inner radius, } \mathrm{m} \\ R_{m} & \text { Radius at the mid sector, } \mathrm{m} \\ R_{p} & \text { Pivot radius, } \mathrm{m}\end{array}$
$W_{p}$ Specific load, N
$(r, \theta, z)$
Cylindrical coordination

\section{Dimensionless parameters}

\begin{tabular}{|c|c|}
\hline$(\bar{R}, \bar{\theta}, \bar{Z})$ & Dimensionless cylindrical Coordinates \\
\hline $\bar{H}$ & Dimensionless film thickness \\
\hline$\overline{M_{r}}$ & Moment in the radial direction \\
\hline$\overline{M_{\theta}}$ & Moment in the circumferential direction \\
\hline $\bar{P}$ & Dimensionless pressure \\
\hline $\bar{R}_{p}=\frac{R_{p}}{R_{m}}=1$ & Dimensionless radius at the pivot \\
\hline $\bar{R}_{e}$ & Dimensionless radius pad outer \\
\hline $\bar{R}_{i}$ & Dimensionless radius pad inner \\
\hline$\mu$ & Dimensionless viscosity \\
\hline$V_{t}$ & $\begin{array}{l}\text { Dimensionless velocity in } \\
\text { circumferential direction }\end{array}$ \\
\hline
\end{tabular}

\section{Greek symbols}

$\alpha$

$\beta \quad$ Angle of inclination in the circumferetial direction, rad

$\psi \quad$ Pad angle, deg

$\mu \quad$ Dynamic viscosity, Pa.s

$\omega \quad$ Rotational speed, rpm

$\theta_{P} \quad$ Pivot circumferential position, deg 